\title{
Associations between smoking behavior-related alleles and the risk of melanoma
}

\author{
Wenting Wu ${ }^{1}$, Hongliang Liu ${ }^{2}$, Fengju Song ${ }^{3}$, Li-Shiun Chen ${ }^{4}$, Peter Kraft ${ }^{5,6,7}$, Qingyi \\ Wei $^{2}$, Jiali Han ${ }^{1}$ \\ ${ }^{1}$ Department of Epidemiology, Richard M. Fairbanks School of Public Health, Melvin and Bren Simon Cancer Center, Indiana \\ University, Indianapolis, Indiana, USA \\ ${ }^{2}$ Duke Cancer Institute, Duke School of Medicine, Durham, North Carolina, USA \\ ${ }^{3}$ Department of Epidemiology and Biostatistics, Key Laboratory of Cancer Prevention and Therapy, National Clinical Research \\ Centre of Cancer, Tianjin Medical University Cancer Institute and Hospital, Tianjin, P. R. China \\ ${ }^{4}$ Department of Psychiatry, Washington University School of Medicine, St. Louis, Missouri, USA \\ ${ }^{5}$ Department of Epidemiology, Harvard School of Public Health, Boston, Massachusetts, USA \\ ${ }^{6}$ Channing Division of Network Medicine, Department of Medicine, Brigham and Women's Hospital, Boston, Massachusetts, USA \\ ${ }^{7}$ Department of Biostatistics, Harvard University School of Public Health, Boston, Massachusetts, USA
}

Correspondence to: Jiali Han, email: jialhan@iu.edu

Keywords: risk of melanoma, smoking behavior, single-nucleotide polymorphisms (SNPs), case-control study, CHRNA5-A3-B4 gene cluster

Received: May 09, 2016

Accepted: June 06, 2016

Published: June 17, 2016

\section{ABSTRACT}

Several studies have reported that cigarette smoking is inversely associated with the risk of melanoma. This study further tested whether incorporating genetic factors will provide another level of evaluation of mechanisms underlying the association between smoking and risk of melanoma. We investigated the association between SNPs selected from genome-wide association studies (GWAS) on smoking behaviors and risk of melanoma using 2,298 melanoma cases and 6,654 controls. Among 16 SNPs, three (rs16969968 [A], rs1051730 [A] and rs2036534 [C] in the 15q25.1 region) reached significance for association with melanoma risk in men $(0.01$ $<=P$ values $<=0.02 ; 0.85<=$ Odds Ratios (ORs) $<=1.20$ ). There was association between the genetic scores based on the number of smoking behavior-risk alleles and melanoma risk with $\boldsymbol{P}$-trend $=\mathbf{0 . 0 0 5}$ among HPFS. Further association with smoking behaviors indicating those three SNPs (rs16969968 [A], rs1051730 [A] and rs2036534 [C]) significantly associated with number of cigarettes smoked per day, CPD, with $P=0.009,0.011$ and 0.001 respectively. The SNPs rs215605 in the PDE1C gene and rs6265 in the $B D N F$ gene significantly interacted with smoking status on melanoma risk (interaction $P=0.005$ and $P=0.003$ respectively). Our study suggests that smoking behavior-related SNPs are likely to play a role in melanoma development and the potential public health importance of polymorphisms in the CHRNA5-A3-B4 gene cluster. Further larger studies are warranted to validate the findings.

\section{INTRODUCTION}

Melanoma is the most lethal form of skin cancer. Incidence and mortality due to melanoma are rising recently in whites [1]. The major host risk factors for melanoma include pigmentation phenotypes, number of melanocytic nevi and a family history of melanoma [2-5]. Tobacco smoke contains numerous carcinogenic compounds and is one of the most important factors for multiple cancers and many other severe diseases [6, 7]. Though smoking is associated with an elevated risk of most cancers, some epidemiological studies have reported a decreased risk of cutaneous malignant melanoma (MM) among smokers [8-11]. Our previous finding showed an inverse association between smoking and melanoma risk, especially on the body site of head and neck [10].

Meanwhile recently, consistent evidence has suggested a genetic basis for smoking behaviors. A few 
studies have reported associations between polymorphisms in the CHRNA5-A3-B4 gene cluster and serum cotinine levels, smoking intensity, suggesting a genetic basis for smoking behaviors [7, 12, 13]. Genetic polymorphisms in the CHRNA5 is associated with intensity of smoking and nicotine dependence. The strongest associations previously published are for rs16969968 and rs 1051730 with smoking quantity $[7,14]$. The rs6265, a nonsynonymous SNP in the $B D N F$ gene, was strongly associated with smoking initiation, and rs7872903 near the $D B H$ gene was significantly associated with smoking cessation [15]. Incorporating genetic factors will provide another level of evaluation of mechanisms underlying the association between smoking and melanoma risk. Hence, we performed an association study on smoking behaviorrelated genetic variants selected from recent genome-wide association studies (GWAS) and the risk of melanoma. Furthermore, five harmonized smoking phenotypes: smoking initiation, number of cigarettes smoked per day (CPD) and pack years, years since quit smoking in former smokers and smoking cessation were investigated in our study. We analyzed associations between those SNPs and each smoking phenotype, as well as SNP-by-smoking interaction to comprehensively understand the relations between SNPs, smoking behaviors and risk of melanoma.

\section{RESULTS}

\section{Population characteristics}

We combined data from two GWAS on melanoma: the nested case-control study within the Nurses' Health Study (NHS) and Health Professionals Follow-up Study (HPFS) (494 cases and 5,628 controls) and the MD Anderson Cancer Center melanoma case-control study (1,804 cases and 1,026 controls) (Table 1, Supplementary Material: Table S1) [16]. Detailed descriptions of these two studies are presented in the online Supplementary Methods (Supplementary Material). Single-nucleotide polymorphisms (SNP) significantly associated with smoking phenotype in Caucasian populations were selected from five existing GWAS and meta-GWAS.

\section{Association of selected loci with risk of melanoma}

Power calculations showed that our combined samples had an $80 \%$ power to detect variants, conferring an OR of 1.18 with an allele frequency of $10 \%$. SNPs rs16969968 and rs1051730 in the 15q25.1 CHRNA5$A 3-B 4$ gene cluster reached nominal significance $(\mathrm{OR}=0.91,95 \% \mathrm{CI}(0.83-0.99), P=0.03$ and $\mathrm{OR}=0.91$, 95\% CI (0.84-1.00), $P=0.05)$. Rs2036534, another SNP located in $15 \mathrm{q} 25.1$, was also associated with an increased risk of melanoma, OR $=1.14$ (95\% CI: 1.03-1.26; $P=0.01$ ) (Table 2 ). When we stratified by sex, we observed stronger association between SNPs rs1051730, rs578776 and rs6495308 in the CHRNA3 gene, rs16969968 in the CHRNA5 gene, rs2036534 in HYKK gene and risk of melanoma among men in the HPFS (OR for rs $1051730=0.77,95 \% \mathrm{CI}(0.60-0.97)(P=0.03)$; OR for rs578776 $=1.44,95 \% \mathrm{CI}(1.14-1.80)(P=0.002)$; OR for rs6495308 $=1.44,95 \% \mathrm{CI}(1.13-1.83)(P=0.003)$; OR for rs $16969968=0.74,95 \%$ CI $(0.58-0.94)(P=0.014)$; and OR for $\mathrm{rs} 2036534=1.39,95 \%$ CI $(1.09-1.77)$ $(P=0.008)$. After Bonferroni correction ( $P$ for statistical significance $<0.05 / 16$ SNPs), a marginally significant association with risk of melanoma was observed for rs6495308 and rs578776 (Tables 2, 3 and Supplementary Material: Table S2). We examined the potential cumulative effects of the 14 independent SNPs in the NHS and HPFS by examining associations between the genetic score and melanoma risk. The genetic scores in our dataset ranged from 1 to 21. Among men in the HPFS, compared with the lowest genetic score quartile (1-8), ORs for the second (9-10), third (11-12), and fourth (13-21) quartiles were 1.23 (95\% CI, $0.73-2.07), 1.97$ (95\% CI, 1.22-3.17), and $1.78(95 \%$ CI, 1.11-2.86), respectively $(P$-trend $=0.005)$.

\section{Associations between SNPs and multiple smoking behaviors in the HPFS and NHS}

We further analyzed the associations between those SNPs and multiple smoking behaviors in the HPFS and NHS. The SNPs rs1051730, rs16969968 and rs2036534 were significantly associated with smoking quantity (CPD) ( $P=0.011, P=0.009$ and $P=0.001$ respectively). The SNPs rs6265, rs6495308 and rs7937 were significantly associated with smoking initiation $(P=0.017, P=0.032$ and $P=0.014$ respectively). SNP rs2036534 risk allele (C) was associated with smoking cessation $(\beta=0.184$, $P=0.033)$, which is consistent with protective effect in smoking quantity $(\beta=-0.143, P=0.001)$. Similar associations was observed for pack years when compare with another smoking quantity phenotype CPD (Table 4).

\section{Interaction between SNPs and smoking status in the HPFS and NHS set}

We further tested the effect modification by smoking status on the associations between SNPs and risk of melanoma. The SNPs rs215605 in the PDE1C gene and rs6265 in the BDNF gene significantly interacted with smoking status on melanoma risk (interaction $P=0.005$ and $P=0.003$ respectively). After Bonferroni correction, rs6265 was still significant and rs215605 was marginally significant; whereas both SNPs remained significant with FDR correction. Within current smoker, melanoma risk was increased $(\beta=0.694, P=0.006)$ for rs215605 risk allele $\mathrm{G}$, whereas in never smoker risk the $\mathrm{G}$ allele had a weak inverse association with risk $(\beta=-0.211, P=0.043)$. For rs6265 risk allele T, it was associated with an elevated 
Table 1: Characteristics of melanoma cases and controls in the NHS and HPFS

\begin{tabular}{|c|c|c|c|}
\hline & \multicolumn{3}{|c|}{ NHS and HPFS } \\
\hline & $\begin{array}{c}\text { All } \\
N=6122\end{array}$ & $\begin{array}{c}\text { Cases } \\
N=494\end{array}$ & $\begin{array}{l}\text { Controls } \\
N=5628\end{array}$ \\
\hline Male $(n, \%)$ & $2428(39.66)$ & $177(35.83)$ & $2251(40.00)$ \\
\hline Female $(n, \%)$ & $3694(60.34)$ & $317(64.17)$ & $3377(60.00)$ \\
\hline Age $($ mean $\pm \mathrm{SD})$ & $43.46 \pm 7.69$ & $43.12 \pm 7.86$ & $43.49 \pm 7.67$ \\
\hline Family history of melanoma (\%) & 7.53 & 17.2 & 6.68 \\
\hline \multicolumn{4}{|l|}{ Smoking Variables } \\
\hline \multicolumn{4}{|l|}{ Smoking status } \\
\hline Never $(n, \%)$ & $2628(47.17)$ & $224(47.36)$ & $2404(47.16)$ \\
\hline Past smoker $(n, \%)$ & $2351(42.20)$ & $214(45.24)$ & $2137(41.92)$ \\
\hline Current smoker $(n, \%)$ & $592(10.63)$ & $35(7.40)$ & $557(10.93)$ \\
\hline Ever Smoker $(n, \%)$ & $2943(52.83)$ & $249(52.64)$ & $2694(52.85)$ \\
\hline \multicolumn{4}{|l|}{ Duration of Smoking } \\
\hline Never $(n, \%)$ & $2628(48.19)$ & $224(48.07)$ & $2404(48.21)$ \\
\hline$<20$ years $(n, \%)$ & $1316(24.13)$ & $116(24.89)$ & $1200(24.06)$ \\
\hline $20-29$ years $(n, \%)$ & $536(9.83)$ & $52(11.16)$ & $484(9.70)$ \\
\hline $30+$ years $(n, \%)$ & $973(17.84)$ & $74(15.88)$ & $899(18.03)$ \\
\hline Pack years for smokers $($ Mean $\pm \mathrm{SD})$ & $16.91 \pm 19.25$ & $15.47 \pm 17.86$ & $17.05 \pm 19.38$ \\
\hline \multicolumn{4}{|l|}{$\begin{array}{l}\text { Cigarettes Smoked Per day in ever } \\
\text { smokers }\end{array}$} \\
\hline Never $(n, \%)$ & $2628(47.17)$ & $224(47.16)$ & $2404(47.36)$ \\
\hline $1-14(n, \%)$ & $1282(23.01)$ & $119(22.81)$ & $1163(25.16)$ \\
\hline $15+(n, \%)$ & $1661(29.82)$ & $130(30.03)$ & $1531(27.48)$ \\
\hline \multicolumn{4}{|l|}{ Yeas since quitting in past smokers } \\
\hline $10+$ years $(n, \%)$ & $1773(75.74)$ & $156(72.90)$ & $1617(76.02)$ \\
\hline$<10$ years $(n, \%)$ & $568(24.26)$ & $58(27.10)$ & $510(23.98)$ \\
\hline
\end{tabular}

risk of melanoma in never smoker $(\beta=0.275, P=0.019)$ and had no significant association in both current smokers and ever smokers (Table 5).

\section{DISCUSSION}

This study consisted of comprehensive analysis amongst genetic variations, smoking quantity, and risk of melanoma. We observed an inverse association between smoking behavior related genetic variants in $15 \mathrm{q} 25.1$ region and risk of melanoma, especially in men, which is consistent with our previous cohort study findings $[7,10]$.

Cluster of two genes CHRNA5 and CHRNA3 on the chromosome $15 \mathrm{q} 25$ region, which encodes neuronal nicotinic acetylcholine receptor subunits, is associated with nicotine dependence and smoking quantity [7]. Various meta-analyses based on subjects of European ancestry identified robust associations for rs16969968 in the gene CHRNA5 and rs1051730 in the CHRNA3 with smoking quantity (number of cigarettes smoked per day) [7, 14, 15, 17]. Especially, rs16969968, a nonsynonymous variant, was indicated with functions of altering nicotinic receptor conductance in vitro by amino acid change in the CHRNA5 [7, 18, 19]. Those two loci have been found to be associated with lung cancer, chronic obstructive pulmonary disease and body mass index in never smokers [13, 20-23]. Based on our study, both rs 1051730 allele (A) in CHRNA3 gene and rs16969968 allele (A) in CHRNA5 
Table 2: Associations between smoking behavior-related SNPs and melanoma risk

\begin{tabular}{|c|c|c|c|c|c|c|c|c|c|c|c|c|c|c|c|c|}
\hline \multirow[b]{2}{*}{ SNP } & \multirow[b]{2}{*}{ CHR } & \multirow[b]{2}{*}{ Gene } & \multirow[b]{2}{*}{$\begin{array}{l}\text { Reference } \\
\text { Number }\end{array}$} & \multicolumn{6}{|c|}{$\mathbf{A l l}^{\mathrm{c}}$} & \multicolumn{3}{|c|}{ Men $^{\mathrm{c}}$} & \multicolumn{3}{|c|}{ Women $^{\mathrm{c}}$} & \multirow[b]{2}{*}{ CytoBand } \\
\hline & & & & Risk & Ref & $\begin{array}{c}\text { Allele } \\
\text { frequency }\end{array}$ & OR & $95 \% \mathrm{CI}$ & $\boldsymbol{P}$ & OR & $95 \% \mathrm{CI}$ & $P$ & OR & $95 \% \mathrm{CI}$ & $\boldsymbol{P}$ & \\
\hline $\operatorname{rs} 215605^{\mathrm{a}}$ & 7 & PDE1C & {$[30]$} & G & $\mathrm{T}$ & 0.38 & 1.01 & $0.92-1.10$ & 0.9 & 0.99 & $0.88-1.12$ & 0.88 & 1.01 & $0.89-1.15$ & 0.85 & $7 \mathrm{p} 14.3$ \\
\hline rs $11782673^{b}$ & 8 & PTK2B & {$[17]$} & G & A & 0.17 & 1.09 & $0.97-1.22$ & 0.14 & 1.02 & $0.87-1.19$ & 0.85 & 1.14 & $0.98-1.33$ & 0.09 & $8 \mathrm{p} 21.2$ \\
\hline $\operatorname{rs} 6474412^{\mathrm{a}}$ & 8 & $\begin{array}{l}\text { SMIM19, } \\
\text { CHRNB3 }\end{array}$ & {$[30]$} & $\mathrm{C}$ & $\mathrm{T}$ & 0.23 & 1.02 & $0.93-1.13$ & 0.63 & 1.13 & $0.98-1.3$ & 0.09 & 0.92 & $0.8-1.07$ & 0.28 & $8 \mathrm{p} 11.21$ \\
\hline rs $13280604^{\mathrm{a}}$ & 8 & CHRNB3 & {$[30]$} & G & A & 0.23 & 1.02 & $0.92-1.13$ & 0.69 & 1.12 & $0.97-1.28$ & 0.13 & 0.93 & $0.8-1.07$ & 0.30 & $8 \mathrm{p} 11.21$ \\
\hline rs $7872903^{a}$ & 9 & FAM163B, DBH & {$[15]$} & $\mathrm{C}$ & $\mathrm{T}$ & 0.21 & 1.00 & $0.91-1.11$ & 0.98 & 1.01 & $0.88-1.17$ & 0.88 & 0.99 & $0.86-1.14$ & 0.91 & $9 \mathrm{q} 34.2$ \\
\hline rs $1329650^{\mathrm{a}}$ & 10 & HECTD2-AS1 & {$[15]$} & $\mathrm{T}$ & G & 0.28 & 0.97 & $0.88-1.07$ & 0.54 & 1.00 & $0.87-1.14$ & 1.00 & 0.95 & $0.83-1.08$ & 0.43 & $10 q 23.32$ \\
\hline $\mathrm{rs} 1013442^{\mathrm{a}}$ & 11 & BDNF-AS & {$[15]$} & $\mathrm{T}$ & A & 0.25 & 1.02 & $0.92-1.13$ & 0.67 & 1.09 & $0.95-1.26$ & 0.22 & 0.97 & $0.84-1.11$ & 0.66 & $11 \mathrm{p} 14.1$ \\
\hline rs $6265^{\mathrm{a}}$ & 11 & BDNF & {$[15]$} & $\mathrm{T}$ & $\mathrm{C}$ & 0.19 & 1.04 & $0.94-1.16$ & 0.44 & 1.13 & $0.97-1.32$ & 0.10 & 0.97 & $0.83-1.13$ & 0.67 & $11 \mathrm{p} 14.1$ \\
\hline rs $2036534^{b}$ & 15 & HYKK & {$[30]$} & $\mathrm{C}$ & $\mathrm{T}$ & 0.22 & 1.14 & $1.03-1.26$ & 0.01 & 1.20 & $1.04-1.38$ & 0.01 & 1.07 & $0.93-1.24$ & 0.33 & $15 \mathrm{q} 25.1$ \\
\hline rs $588765^{b}$ & 15 & CHRNA5 & {$[14,17]$} & $\mathrm{T}$ & $\mathrm{C}$ & 0.42 & 1.02 & $0.94-1.11$ & 0.59 & 1.03 & $0.91-1.16$ & 0.64 & 1.00 & $0.89-1.13$ & 1.00 & $15 \mathrm{q} 25.1$ \\
\hline rs16969968 & 15 & CHRNA5 & {$[15,17,30]$} & A & G & 0.35 & 0.91 & $0.83-0.99$ & 0.03 & 0.85 & $0.75-0.96$ & 0.01 & 0.99 & $0.87-1.12$ & 0.86 & $15 \mathrm{q} 25.1$ \\
\hline rs578776 ${ }^{a}$ & 15 & CHRNA3 & {$[14]$} & A & G & 0.28 & 1.08 & $0.99-1.18$ & 0.1 & 1.20 & $0.87-1.66$ & 0.27 & 1.01 & $0.89-1.15$ & 0.85 & $15 \mathrm{q} 25.1$ \\
\hline rs $1051730^{\mathrm{a}}$ & 15 & CHRNA3 & {$[15,17,30]$} & A & G & 0.34 & 0.91 & $0.84-1.00$ & 0.05 & 0.86 & $0.76-0.98$ & 0.02 & 0.99 & $0.88-1.13$ & 0.92 & $15 \mathrm{q} 25.1$ \\
\hline rs6495308 & 15 & CHRNA3 & {$[17]$} & $\mathrm{C}$ & $\mathrm{T}$ & 0.23 & 1.08 & $0.98-1.20$ & 0.11 & 1.19 & $1.03-1.36$ & 0.01 & 0.99 & $0.86-1.14$ & 0.89 & $15 \mathrm{q} 25.1$ \\
\hline rs $7937^{\mathrm{a}}$ & 19 & MIA-RAB4B & {$[30]$} & $\mathrm{C}$ & $\mathrm{T}$ & 0.44 & 0.94 & $0.86-1.02$ & 0.13 & 0.86 & $0.76-0.97$ & 0.01 & 1.02 & $0.91-1.15$ & 0.70 & $19 \mathrm{q} 13.2$ \\
\hline rs $3733829^{a}$ & 19 & RAB4B-EGLN2 & {$[15]$} & G & A & 0.36 & 0.96 & $0.88-1.04$ & 0.32 & 0.95 & $0.84-1.07$ & 0.38 & 0.96 & $0.84-1.08$ & 0.47 & $19 q 13.2$ \\
\hline
\end{tabular}

Abbreviations: CHR, chromosome; OR, odds ratio; SNP, single-nucleotide polymorphism.

a. SNPs reached genome-wide significance $\left(P\right.$ value $\left.=5 \times 10^{-8}\right)$ with smoking behaviors.

b. SNPs did not reach $P$ value of $5 \times 10^{-8}$.

c. Meta-analysis results for both NHS and HPFS set and MD Anderson set.

Table 3: Associations between smoking behavior-related SNPs and melanoma risk in men and women

\begin{tabular}{|c|c|c|c|c|c|c|c|c|c|c|c|c|}
\hline \multirow[b]{3}{*}{ SNP } & \multirow[b]{3}{*}{ CHR } & \multirow[b]{3}{*}{ Gene } & \multicolumn{6}{|c|}{ Men } & \multicolumn{4}{|c|}{ Women } \\
\hline & & & \multicolumn{4}{|c|}{ HPFS set } & \multicolumn{2}{|c|}{ MD Anderson set } & \multicolumn{2}{|c|}{ NHS set } & \multicolumn{2}{|c|}{ MD Anderson set } \\
\hline & & & Risk & Ref & OR & $P$ & OR & $P$ & OR & $P$ & OR & $P$ \\
\hline rs215605 & 7 & PDE1C & $\mathrm{G}$ & $\mathrm{T}$ & 0.99 & 0.945 & 0.99 & 0.90 & 0.92 & 0.36 & 1.12 & 0.22 \\
\hline rs $11782673^{b}$ & 8 & PTK2B & G & A & 1.04 & 0.785 & 1.01 & 0.96 & 1.19 & 0.10 & 1.09 & 0.48 \\
\hline rs $6474412^{a}$ & 8 & SMIM19, CHRNB3 & $\mathrm{C}$ & $\mathrm{T}$ & 1.36 & 0.016 & 1.04 & 0.69 & 0.91 & 0.35 & 0.94 & 0.57 \\
\hline rs $13280604^{a}$ & 8 & CHRNB3 & G & $\mathrm{A}$ & 1.34 & 0.023 & 1.03 & 0.76 & 0.92 & 0.40 & 0.94 & 0.53 \\
\hline rs $7872903^{a}$ & 9 & FAM163B, DBH & $\mathrm{C}$ & $\mathrm{T}$ & 1.08 & 0.576 & 0.98 & 0.86 & 1.06 & 0.55 & 0.93 & 0.45 \\
\hline rs $1329650^{\mathrm{a}}$ & 10 & HECTD2-AS1 & $\mathrm{T}$ & G & 1.09 & 0.469 & 0.96 & 0.63 & 0.89 & 0.22 & 1.01 & 0.89 \\
\hline rs $1013442^{a}$ & 11 & BDNF-AS & $\mathrm{T}$ & $\mathrm{A}$ & 1.07 & 0.613 & 1.10 & 0.25 & 0.99 & 0.89 & 0.95 & 0.63 \\
\hline rs $6265^{\mathrm{a}}$ & 11 & BDNF & $\mathrm{T}$ & $\mathrm{C}$ & 1.18 & 0.223 & 1.11 & 0.26 & 0.99 & 0.89 & 0.95 & 0.63 \\
\hline rs $2036534^{b}$ & 15 & HYKK & $\mathrm{C}$ & $\mathrm{T}$ & 1.39 & 0.008 & 1.11 & 0.23 & 0.99 & 0.90 & 1.18 & 0.13 \\
\hline rs $588765^{b}$ & 15 & CHRNA5 & $\mathrm{T}$ & $\mathrm{C}$ & 0.99 & 0.959 & 1.04 & 0.55 & 1.03 & 0.75 & 0.97 & 0.74 \\
\hline rs16969968 & 15 & CHRNA5 & A & G & 0.74 & 0.014 & 0.89 & 0.14 & 0.99 & 0.91 & 0.99 & 0.90 \\
\hline $\operatorname{rs} 578776^{a}$ & 15 & CHRNA3 & A & G & 1.44 & 0.002 & 1.03 & 0.71 & 1.01 & 0.92 & 1.02 & 0.86 \\
\hline rs $1051730^{\mathrm{a}}$ & 15 & CHRNA3 & $\mathrm{A}$ & G & 0.77 & 0.030 & 0.90 & 0.17 & 1.01 & 0.90 & 0.97 & 0.78 \\
\hline rs6495308 & 15 & CHRNA3 & $\mathrm{C}$ & $\mathrm{T}$ & 1.44 & 0.003 & 1.08 & 0.37 & 0.96 & 0.71 & 1.02 & 0.85 \\
\hline rs $7937^{a}$ & 19 & MIA-RAB4B & $\mathrm{C}$ & $\mathrm{T}$ & 0.82 & 0.084 & 0.88 & 0.07 & 0.94 & 0.44 & 1.13 & 0.17 \\
\hline rs3733829a & 19 & RAB4B-EGLN2 & G & $\mathrm{A}$ & 0.96 & 0.711 & 0.94 & 0.41 & 0.98 & 0.80 & 0.93 & 0.44 \\
\hline
\end{tabular}

a. SNPs reached genome-wide significance level $\left(P\right.$ value $\left.=5 \times 10^{-8}\right)$ with smoking behaviors.

b. SNPs did not reach $P$ value of $5 \times 10^{-8}$. 
Table 4: Associations between smoking behavior-related SNPs and smoking behaviors among controls of NHS and HPFS

\begin{tabular}{|c|c|c|c|c|c|c|c|c|c|c|c|c|c|c|c|c|c|c|}
\hline \multirow[b]{2}{*}{ SNP } & \multirow[b]{2}{*}{ Risk } & \multirow[b]{2}{*}{ Ref } & \multirow{2}{*}{$\begin{array}{c}\text { Related Smoking } \\
\text { Phenotypes From } \\
\text { Literature }^{\mathrm{a}}\end{array}$} & \multicolumn{3}{|c|}{$\mathrm{CPD}^{\mathrm{b}, \mathrm{c}}$} & \multicolumn{3}{|c|}{ Smoking Cessation ${ }^{\mathrm{b}, \mathrm{c}}$} & \multicolumn{3}{|c|}{ Smoking Initiation ${ }^{\mathrm{b}, \mathrm{c}}$} & \multicolumn{3}{|c|}{ Pack Years $^{\mathrm{b}, \mathrm{c}}$} & \multicolumn{3}{|c|}{$\begin{array}{l}\text { Years since Quit } \\
\text { Smoking }{ }^{\mathrm{b}, \mathrm{c}}\end{array}$} \\
\hline & & & & $\beta$ & s.e. & $P$ & $\beta$ & s.e. & $P$ & $\beta$ & s.e. & $P$ & $\beta$ & s.e. & $P$ & $\beta$ & s.e. & $P$ \\
\hline rs215605 & G & $\mathrm{T}$ & Smoking quantity & -0.002 & 0.038 & 0.952 & 0.113 & 0.072 & 0.118 & -0.056 & 0.041 & 0.176 & -0.165 & 0.536 & 0.758 & 0.003 & 0.027 & 0.912 \\
\hline rs11782673 & G & A & Smoking quantity & -0.036 & 0.049 & 0.468 & 0.064 & 0.093 & 0.491 & -0.028 & 0.054 & 0.596 & -0.785 & 0.698 & 0.261 & 0.005 & 0.035 & 0.883 \\
\hline rs6474412 & $\mathrm{C}$ & $\mathrm{T}$ & Smoking quantity & -0.098 & 0.043 & 0.022 & 0.072 & 0.081 & 0.376 & 0.039 & 0.048 & 0.410 & -1.263 & 0.608 & 0.038 & -0.005 & 0.030 & 0.879 \\
\hline rs13280604 & G & A & Smoking quantity & -0.094 & 0.043 & 0.028 & 0.073 & 0.082 & 0.368 & 0.041 & 0.048 & 0.394 & -1.244 & 0.608 & 0.041 & -0.002 & 0.030 & 0.960 \\
\hline rs 7872903 & $\mathrm{C}$ & $\mathrm{T}$ & Smoking cessation & 0.051 & 0.044 & 0.250 & -0.110 & 0.082 & 0.179 & 0.030 & 0.049 & 0.534 & 0.921 & 0.626 & 0.142 & -0.041 & 0.032 & 0.196 \\
\hline rs 1329650 & $\mathrm{~T}$ & G & Smoking quantity & 0.023 & 0.041 & 0.571 & -0.083 & 0.076 & 0.276 & 0.008 & 0.045 & 0.857 & 0.502 & 0.579 & 0.386 & 0.010 & 0.029 & 0.731 \\
\hline rs1013442 & $\mathrm{T}$ & A & Smoking initiation & 0.084 & 0.042 & 0.044 & -0.130 & 0.077 & 0.092 & -0.051 & 0.046 & 0.265 & 1.274 & 0.589 & 0.031 & 0.028 & 0.029 & 0.341 \\
\hline rs6265 & $\mathrm{T}$ & $\mathrm{C}$ & Smoking initiation & 0.092 & 0.046 & 0.045 & -0.201 & 0.084 & 0.017 & -0.034 & 0.050 & 0.494 & 1.723 & 0.646 & 0.008 & 0.018 & 0.033 & 0.585 \\
\hline rs 2036534 & $\mathrm{C}$ & $\mathrm{T}$ & Smoking quantity & -0.143 & 0.044 & 0.001 & 0.184 & 0.086 & 0.033 & -0.048 & 0.048 & 0.318 & -1.649 & 0.626 & 0.009 & -0.024 & 0.031 & 0.434 \\
\hline rs 588765 & $\mathrm{~T}$ & $\mathrm{C}$ & Smoking quantity & -0.021 & 0.037 & 0.564 & -0.023 & 0.069 & 0.735 & 0.069 & 0.040 & 0.086 & -0.507 & 0.518 & 0.328 & -0.025 & 0.026 & 0.327 \\
\hline rs16969968 & A & G & Smoking quantity & 0.099 & 0.038 & 0.009 & -0.085 & 0.071 & 0.234 & -0.070 & 0.042 & 0.091 & 1.699 & 0.536 & 0.002 & 0.036 & 0.027 & 0.178 \\
\hline rs 578776 & A & G & Smoking quantity & -0.072 & 0.040 & 0.075 & 0.141 & 0.078 & 0.070 & -0.029 & 0.044 & 0.508 & -0.992 & 0.571 & 0.083 & -0.008 & 0.028 & 0.785 \\
\hline rs 1051730 & A & G & Smoking quantity & 0.097 & 0.038 & 0.011 & -0.107 & 0.072 & 0.134 & -0.082 & 0.042 & 0.051 & 1.743 & 0.540 & 0.001 & 0.041 & 0.027 & 0.134 \\
\hline rs6495308 & $\mathrm{C}$ & $\mathrm{T}$ & Smoking quantity & -0.100 & 0.043 & 0.021 & 0.181 & 0.084 & 0.032 & 0.005 & 0.047 & 0.915 & -1.584 & 0.611 & 0.010 & -0.018 & 0.030 & 0.557 \\
\hline rs7937 & $\mathrm{C}$ & $\mathrm{T}$ & Smoking quantity & -0.027 & 0.037 & 0.467 & -0.170 & 0.069 & 0.014 & 0.064 & 0.040 & 0.109 & 0.504 & 0.522 & 0.334 & 0.000 & 0.026 & 0.988 \\
\hline rs 3733829 & G & A & Smoking quantity & -0.071 & 0.037 & 0.059 & 0.050 & 0.071 & 0.488 & -0.004 & 0.041 & 0.928 & -0.270 & 0.531 & 0.611 & -0.018 & 0.026 & 0.503 \\
\hline
\end{tabular}

a. $[14,15,17,30]$.

b. CPD, pack years, and years since quit smoking was analyzed as a continuous variable representing the number of cigarettes smoked per day, number of multiplying years of smoking by the number of cigarettes divided by 20 , years since quit smoking in former smokers, respectively. Smoking initiation and smoking cessation were analyzed as dichotomous variables, contrasting ever versus never and former versus current smokers, respectively.

c. Analyses were adjusted by age, sex and five EVs.

Table 5: Interaction analysis for smoking status and rs215605 and rs6265

\begin{tabular}{|c|c|c|c|c|c|c|c|c|}
\hline SNP & Risk & Ref & Smoking Status & $\beta$ (effect size) & SE (standard error) & $P$-value & Sample Size & $\begin{array}{c}\text { Interaction } P \\
\text { value }^{\mathrm{a}}\end{array}$ \\
\hline \multirow[t]{3}{*}{ rs 215605} & G & $\mathrm{T}$ & Never Smoker & -0.211 & 0.105 & 0.043 & 2628 & \\
\hline & & & Past Smoker & -0.034 & 0.105 & 0.745 & 2351 & 0.005 \\
\hline & & & Current Smoker & 0.694 & 0.254 & 0.006 & 592 & \\
\hline \multirow[t]{3}{*}{ rs 6265} & $\mathrm{~T}$ & $\mathrm{C}$ & Never Smoker & 0.275 & 0.118 & 0.019 & 2628 & \\
\hline & & & Past Smoker & -0.080 & 0.135 & 0.552 & 2351 & 0.003 \\
\hline & & & Current Smoker & -0.636 & 0.375 & 0.090 & 592 & \\
\hline
\end{tabular}

a. Significant after FDR corrections, FDR $P=0.038$ for both SNPs.

gene increased smoking quantity and delayed smoking cessation behaviors, while rs2036534 allele (C) in HYKK gene reduced smoking quantity and enhanced smoking cessation. Multiple genetic risk factors may be involved in the underlying mechanism for the $15 \mathrm{q} 25.1$ region on melanoma development, including increased smoking quantity, and delay in smoking cessation $[7,24,25]$.
Meanwhile we detected trends between genetic variations and smoking quantity (smoking intensity and pack years of smoking), smoking cessation and initiation behaviors, to further investigate underlying mechanisms; the results are consistent with previous reports $[10,15,17]$. Inconsistent results were reported previously for CHRNA5 variants in relation to smoking 
cessation [7, 26-28]. One previous meta-analysis suggested the rs16969968 allele (A) was correlated with delayed smoking cessation [7]. Our results indicated that both CHRNA5 variants rs16969968 allele (A) and rs588765 allele (T) were associated with delay in smoking cessation, which validated the previous finding in a large European cohort study. Besides, we found rs2036534 in $H Y K K$ gene, rs6265 in BDNF gene, rs7937 in MIA-RAB4B gene and rs6495308 in $C H R N A 3$, which previously predicted smoking heaviness or smoking initiation, was also associated with smoking quitting behaviors among ever-smokers. It suggested that multiple genes or genetic variants might mediate smoking cessation [7, 29].

Interestingly, opposite associations of rs215605 in $P D E 1 C$ with risk of melanoma in never and current smokers were observed. An interaction test confirmed that these estimates differed from each other. A previous publication has reported similar phenomena for rs16969968-rs1051730 with an association with body mass index in never smoker [13]. PDE1C has been highlighted in a previous GWAS of nicotine dependence and smoking cessation $[28,30]$. Meanwhile experimental evidence supports its function in driving cell proliferation, migration and invasion in human malignant melanoma cells, glioblastoma multiforme cells, and etc [31, 32]. Evidence of smoking behavior modification was also identified for rs6265 in $B D N F$. BDNF is highly expressed in the brain regions of prefrontal cortex and hippocampus, which is thought to be involved in the cognitive-enhancing effects of nicotine [33]. The rs6265 has been found to be correlated with multiple psychiatric disorders, including schizophrenia, bipolar and eating disorders [34, 35]. Meanwhile, it was recently identified as a genetic risk factor for body mass index [36]. It also indicated that those two SNPs might be weakly associated with risk of melanoma via pathways other than smoking, as well as with changing smoking quantity among smokers, which warrants additional experimental validation.

These results should be interpreted with caution given the multiple testing issues. Meanwhile, the genetic effect of 15q25.1 region was not confirmed in the MD Anderson set, which may be due to heterogeneity of studies. Further large study is warranted to validate these findings. However, to our knowledge, the sample size of this study is among the largest genetic meta-analyses for smoking and melanoma risk investigation. We provided a comprehensive analysis on the relationships between genetic variations, smoking quantity, smoking initiation, smoking cessation and risk of melanoma. Further SNPsmoking interaction analysis suggested a possible modification effect of smoking behaviors.

In conclusion, our study suggested that smoking behavior-related SNPs are likely to play a role in melanoma development. Further studies are warranted to understand the potential functional mechanisms in pathogenesis of melanoma.

\section{MATERIALS AND METHODS}

\section{Harvard NHS \& HPFS sets}

\section{Description of study populations}

\section{Nurses' Health Study}

The Nurses' Health Study (NHS) was established in 1976, when 121700 female registered nurses between the ages of 30 and 55 years residing in 11 larger US states completed and returned an initial self-administered questionnaire on their medical histories and baseline health-related exposures. Biennial questionnaires with collection of exposure information on risk factors have been collected prospectively. Every 2 years, along with exposures, outcome data with appropriate follow-up of reported disease events are collected. Overall, followup has been high; after more than 20 years, $90 \%$ of participants continue to complete questionnaires. From May 1989 through September 1990, we collected blood samples from 32826 participants in the NHS. Information on melanoma development was first collected in the 1984 questionnaire.

\section{Health Professionals Follow-up Study}

In 1986, 51,529 men from all 50 US states in health professions (dentists, pharmacists, optometrists, osteopath physicians, podiatrists, and veterinarians) aged 40-75 years answered a detailed mailed questionnaire, forming the basis of the study. The average followup rate for this cohort over 10 years is $>90 \%$. On each biennial questionnaire, we obtained disease- and healthrelated information. Between 1993 and 1994, 18,159 study participants provided blood samples by overnight courier. Information on melanoma development was first collected in the 1986 questionnaire. Description of the study population can be found elsewhere [37].

\section{Melanoma cases and controls in the discovery set}

Eligible cases in the NHS and the Health Professionals Follow-up Study (HPFS) consisted of participants with pathologically confirmed invasive melanoma, diagnosed any time after baseline up to the 2008 follow-up cycle for both cohorts. All subjects were United States non-Hispanic Caucasians.

We have previously conducted several GWASs on different disease outcomes (NHS: breast cancer, coronary heart disease, type 2 diabetes, kidney stone, pancreatic cancer, and glaucoma; HPFS: coronary heart disease, type 2 diabetes, kidney stone, advanced prostate cancer, and glaucoma). The study population for eight GWAS sets of the discovery set is presented in following descriptions. We included only controls in each GWAS, except for the kidney stone GWAS, in which we used both cases and controls. Participants without melanoma diagnosis were the controls in the current study, and those with melanoma 
diagnosis were the cases. In addition, we genotyped the rest of the melanoma cases in both cohorts who were not included in these previous GWASs. The Institutional Review Board at Harvard T.H. Chan School of Public Health and Brigham and Women's Hospital, Harvard Medical School, approved the study protocols.

Informed consent was obtained from all participants. Finally, we included 494 melanoma cases and 5628 controls.

\section{Laboratory assays}

Genotyping in eight GWASs of the discovery set. We performed genotyping in the breast cancer GWAS in NHS using the Illumina HumanHap550 array, as part of the National Cancer Institute's Cancer Genetic Markers of Susceptibility Project. For the coronary heart disease and type 2 diabetes GWASs of the discovery set, we performed genotyping using the Affymetrix 6.0 array. For the glaucoma GWAS, we performed genotyping using the Illumina HumanHap660 array. For the kidney stone, advanced prostate cancer, and melanoma GWASs, we performed genotyping using the Illumina HumanHap610 array. The quality control procedures for eight GWAS sets of the discovery set are presented in following description.

\section{Imputation and meta-analysis}

On the basis of the genotyped single-nucleotide polymorphisms (SNPs) and haplotype information in the National Center for Biotechnology Information build 35 of phase II Hapmap CEU data, we imputed genotypes for $>2.5$ million SNPs using the program MACH [38]. Only SNPs with imputation quality $R^{2}>0.95$ in each study were included in the final analysis. A total of 1579307 SNPs were included in the final meta-analysis of the NHS and HPFS.

\section{M.D. Anderson cancer center set}

The study participants for the discovery analysis were from a hospital-based case-control study of melanoma, for which cases were recruited from among non-Hispanic white patients and controls at MD Anderson between March 1998 and August 2008. Samples and data were available from 931 melanoma patients and 1,026 cancer-free controls (friends of other patients reporting to clinics), which were frequency-matched on age and sex, completed a comprehensive skin lifestyle questionnaire, and passed quality control filters for genotyping. This questionnaire was administered by an interviewer to $70 \%$ of patients and controls and was selfadministered for the remaining 30\%. An additional case series comprising 873 individuals presenting for treatment for melanoma at MD Anderson was also included, bringing the total number of melanoma patients to 1,804 .
The study protocols were approved by the Institutional Review Board at MD Anderson, and informed consent was obtained from all participants.

Tissue samples were collected as whole blood, with various DNA extraction methods (including Gentra, Qiagen, and phenol/chloroform). DNA samples for the first-stage genome-wide association study were genotyped using the Illumina Omnil-Quad array and were called using the BeadStudio algorithm, at the John Hopkins University Center for Inherited Disease Research (CIDR).

\section{QC procedures for the M.D. Anderson set}

Mean call rate for all samples was $99.86 \%$. Only 41 failed genotyping with $>10 \%$ missing rate across all SNPs, and 11 samples had identity problems that could not be resolved. For this study, the IBD coefficients were estimated using 116,002 autosomal SNPs in PLINK (Purcell et al., 2007). In total, 126 duplicated, related (IBD), or outliers identified by PCA were excluded from the study. Following these exclusions there were 1,952 cases and 1,026 controls. Among 2,978 total cases and controls passing quality control, 138 in situ cases were subsequently removed from the study for indeterminate phenotype. Ten atypical melanocytic proliferation (AMPs) patients were also excluded as not having invasive cancers. Finally, we analyzed data from 1,804 cases and 1,026 controls available for the association study of melanoma susceptibility (Amos et al., 2011).

\section{Smoking behavior-related GWASs SNPs selection}

A total of 36 SNPs were selected from published GWAS or meta-analysis of GWAS on smoking behaviors $[14,15,17,25,30]$. Four carefully harmonized smoking phenotypes were included in this study - smoking initiation (ever versus never been a regular smoker), age of smoking initiation, smoking quantity (number of cigarettes smoked per day, CPD) and smoking cessation (former versus current smokers) - among people of European ancestry. 10 SNPs not available in either melanoma data set were excluded. For SNPs with high linkage disequilibrium (LD), which was characterized by $r^{2}>0.8$ according to the HapMap 3 (release 2) [39], only one SNP was kept, except for SNPs rs16969968 and rs1051730 located in the CHRNA5-A3-B4 gene cluster. A total of 16 smoking behavior-related SNPs were finally included for analysis.

\section{Statistical analysis}

A total of 16 SNPs were selected and divided into two groups: those associated with smoking phenotype risk with $P$ value $<5 \times 10^{-8}$ were in group 1 , and those highly associated with smoking phenotype risk that failed to reach that $P$ value were in group 2 . 
For SNPs with a high LD, only those with the smallest $P$ value were chosen for the genetic score summary. We used unconditional logistic regression to calculate OR and $95 \%$ confidence interval (CI) with adjustment for age, sex, history of melanoma and five eigenvectors $(\mathrm{EV})$, which were calculated for all individuals on the basis of approximately 10,000 unlinked markers with the EIGENSTRAT software. Betas from each study were combined by a meta-analysis with weights proportional to the inverse variance of the beta in each study. We calculated a genetic score on the basis of the presence of total copy number of 14 independent smokingrelated risk alleles in the NHS and HPFS. The score was logistically regressed against the melanoma case status, adjusting for age, sex, history of melanoma and five EVs. Subgroup analyses were performed for men and women.

Five carefully harmonized smoking phenotypes were included in further analysis - smoking initiation (ever versus never been a regular smoker), smoking quantity (number of cigarettes smoked per day (CPD) and pack years), years since quit smoking in former smokers and smoking cessation (former versus current smokers) - among controls of the NHS and HPFS. We performed association analyses separately under an additive model using covariate effects for age, sex and five EVs. The primary gene - smoking status interaction analytic model included SNP, smoking status and SNP $\times$ smoking status interaction term, as well as age, sex and the first five principal components as covariates:

Melanoma diagnosis $\sim$ age + sex + smoking status + pc. $1+$ pc. $2+p c .3+$ pc. $4+$ pc. $5+$ genotype + genotype *smoking status. Both Bonferroni and false discovery rate (FDR) methods were considered for multiple testing issues [40].

\section{Abbreviations}

SNP: Single nucleotide polymorphism; GWAS: genome-wide association studies; HPFS: Health Professionals Follow-up Study; NHS: Nurses' Health Study; CHRNA3: cholinergic receptor, nicotinic alpha 3; CHRNA5: cholinergic receptor, nicotinic alpha 5; OR: Odds ratio; SD: Standard deviation.

\section{ACKNOWLEDGMENTS}

We would like to thank the participants and staff of the Nurses' Health Study, the Health Professionals Follow-Up Study, and the M. D. Anderson Cancer Center melanoma case-control study for their valuable contributions as well as the following state cancer registries for their help: $\mathrm{AL}, \mathrm{AZ}, \mathrm{AR}, \mathrm{CA}, \mathrm{CO}, \mathrm{CT}, \mathrm{DE}$, FL, GA, ID, IL, IN, IA, KY, LA, ME, MD, MA, MI, NE, NH, NJ, NY, NC, ND, OH, OK, OR, PA, RI, SC, TN, TX, VA, WA, WY. The authors assume full responsibility for analyses and interpretation of these data.

\section{CONFLICTS OF INTEREST}

The authors state no conflicts of interest.

\section{GRANT SUPPORT}

This work was in part supported by NIH R01 CA49449, P01 CA87969, UM1 CA186107 and UM1 CA167552.

\section{REFERENCES}

1. Bloethner S, Scherer D, Drechsel M, Hemminki K, Kumar R. Malignant melanoma - a genetic overview. Actas Dermosifiliogr. 2009; 100:38-51.

2. Law MH, Bishop DT, Lee JE, Brossard M, Martin NG, Moses EK, Song F, Barrett JH, Kumar R, Easton DF, Pharoah PDP, Swerdlow AJ, Kypreou KP, et al. Genomewide meta-analysis identifies five new susceptibility loci for cutaneous malignant melanoma. Nature genetics. 2015; 47:987-995.

3. Holly EA, Aston DA, Cress RD, Ahn DK, Kristiansen JJ. Cutaneous melanoma in women. II. Phenotypic characteristics and other host-related factors. Am J Epidemiol. 1995; 141:934-942.

4. Holly EA, Aston DA, Cress RD, Ahn DK, Kristiansen JJ. Cutaneous melanoma in women. I. Exposure to sunlight, ability to tan, and other risk factors related to ultraviolet light. Am J Epidemiol. 1995; 141:923-933.

5. Titus-Ernstoff L, Perry AE, Spencer SK, Gibson JJ, Cole BF, Ernstoff MS. Pigmentary characteristics and moles in relation to melanoma risk. Int J Cancer. 2005; 116:144-149.

6. Secretan B, Straif K, Baan R, Grosse Y, El Ghissassi F, Bouvard V, Benbrahim-Tallaa L, Guha N, Freeman C, Galichet L, Cogliano V, Group WHOIAfRoCMW, Gupta PC, et al. A review of human carcinogens--Part E: tobacco, areca nut, alcohol, coal smoke, and salted fish. Lancet Oncol. 2009; 10:1033-1034.

7. Chen L-S, Hung RJ, Baker T, Horton A, Culverhouse R, Saccone N, Cheng I, Deng B, Han Y, Hansen HM, Horsman J, Kim C, Lutz S, et al. CHRNA5 risk variant predicts delayed smoking cessation and earlier lung cancer diagnosis - a meta-analysis. J Natl Cancer I. 2015; 107.

8. De Hertog SAE, Wensveen CAH, Bastiaens MT, Kielich CJ, Berkhout MJP, Westendorp RGJ, Vermeer BJ, Bavinck JNB, Study LSC. Relation between smoking and skin cancer. J Clin Oncol. 2001; 19:231-238.

9. Freedman DM, Sigurdson A, Doody MM, Rao RS, Linet MS. Risk of melanoma in relation to smoking, alcohol intake, and other factors in a large occupational cohort. Cancer causes \& control. 2003; 14:847-857.

10. Song FJ, Qureshi AA, Gao X, Li TC, Han JL. Smoking and risk of skin cancer: a prospective analysis and a metaanalysis. Int J Epidemiol. 2012; 41:1694-1705. 
11. Henderson MT, Kubo JT, Desai M, David SP, Tindle H, Sinha AA, Seiffert-Sinha K, Hou L, Messina C, Saquib N, Stefanick ML, Tang JY. Smoking behavior and association of melanoma and nonmelanoma skin cancer in the Women's Health Initiative. Journal of the American Academy of Dermatology. 2015; 72:190-191 e193.

12. Spitz MR, Amos CI, Bierut LJ, Caporaso NE. Cotinine Conundrum-A Step Forward but Questions Remain. J Natl Cancer I. 2012; 104:720-722.

13. Taylor AE, Morris RW, Fluharty ME, Bjorngaard JH, Asvold BO, Gabrielsen ME, Campbell A, Marioni R, Kumari M, Hallfors J, Mannisto S, Marques-Vidal P, Kaakinen $M$, et al. Stratification by smoking status reveals an association of CHRNA5-A3-B4 genotype with body mass index in never smokers. PLoS genetics. 2014; 10:e1004799.

14. Saccone NL, Culverhouse RC, Schwantes-An TH, Cannon DS, Chen X, Cichon S, Giegling I, Han S, Han Y, Keskitalo-Vuokko K, Kong X, Landi MT, Ma JZ, et al. Multiple independent loci at chromosome 15q25.1 affect smoking quantity: a meta-analysis and comparison with lung cancer and COPD. PLoS genetics. 2010; 6.

15. Tobacco and Genetics C. Genome-wide meta-analyses identify multiple loci associated with smoking behavior. Nature genetics. 2010; 42:441-447.

16. Nan H, Xu M, Zhang J, Zhang M, Kraft P, Qureshi AA, Chen C, Guo Q, Hu FB, Rimm EB, Curhan G, Song Y, Amos CI, et al. Genome-wide association study identifies nidogen 1 (NID1) as a susceptibility locus to cutaneous nevi and melanoma risk. Hum Mol Genet. 2011; 20:2673-2679.

17. Liu JZ, Tozzi F, Waterworth DM, Pillai SG, Muglia P, Middleton L, Berrettini W, Knouff CW, Yuan X, Waeber G, Vollenweider P, Preisig M, Wareham NJ, et al. Metaanalysis and imputation refines the association of $15 \mathrm{q} 25$ with smoking quantity. Nature genetics. 2010; 42:436-440.

18. Tseng TS, Park JY, Zabaleta J, Moody-Thomas S, Sothern MS, Chen T, Evans DE, Lin HY. Role of nicotine dependence on the relationship between variants in the nicotinic receptor genes and risk of lung adenocarcinoma. PloS one. 2014; 9:e107268.

19. Kuryatov A, Berrettini W, Lindstrom J. Acetylcholine receptor (AChR) alpha5 subunit variant associated with risk for nicotine dependence and lung cancer reduces (alpha4beta2) alpha5 AChR function. Mol Pharmacol. 2011; 79:119-125.

20. Thorgeirsson TE, Geller F, Sulem P, Rafnar T, Wiste A, Magnusson KP, Manolescu A, Thorleifsson G, Stefansson H, Ingason A, Stacey SN, Bergthorsson JT, Thorlacius S, et al. A variant associated with nicotine dependence, lung cancer and peripheral arterial disease. Nature. 2008; 452:638-642.

21. Amos CI, Wu X, Broderick P, Gorlov IP, Gu J, Eisen T, Dong Q, Zhang Q, Gu X, Vijayakrishnan J, Sullivan K, Matakidou A, Wang Y, et al. Genome-wide association scan of tag SNPs identifies a susceptibility locus for lung cancer at $15 \mathrm{q} 25.1$. Nature genetics. 2008; 40:616-622.

22. Hung RJ, McKay JD, Gaborieau V, Boffetta P, Hashibe M, Zaridze D, Mukeria A, Szeszenia-Dabrowska N, Lissowska J, Rudnai P, Fabianova E, Mates D, Bencko V, et al. A susceptibility locus for lung cancer maps to nicotinic acetylcholine receptor subunit genes on $15 \mathrm{q} 25$. Nature. 2008; 452:633-637.

23. Brennan P, Hainaut P, Boffetta P. Genetics of lung-cancer susceptibility. Lancet Oncol. 2011; 12:399-408.

24. Saccone NL, Wang JC, Breslau N, Johnson EO, Hatsukami D, Saccone SF, Grucza RA, Sun L, Duan W, Budde J, Culverhouse RC, Fox L, Hinrichs AL, et al. The CHRNA5-CHRNA3-CHRNB4 nicotinic receptor subunit gene cluster affects risk for nicotine dependence in AfricanAmericans and in European-Americans. Cancer research. 2009; 69:6848-6856.

25. Chen LS, Saccone NL, Culverhouse RC, Bracci PM, Chen CH, Dueker N, Han Y, Huang H, Jin G, Kohno T, Ma JZ, Przybeck TR, Sanders AR, et al. Smoking and genetic risk variation across populations of European, Asian, and African American ancestry - a metaanalysis of chromosome $15 \mathrm{q} 25$. Genetic epidemiology. 2012; 36:340-351.

26. Breitling LP, Twardella D, Hoffmann MM, Witt SH, Treutlein J, Brenner $H$. Prospective association of dopamine-related polymorphisms with smoking cessation in general care. Pharmacogenomics. 2010; 11:527-536.

27. Conti DV, Lee W, Li D, Liu J, Van Den Berg D, Thomas PD, Bergen AW, Swan GE, Tyndale RF, Benowitz NL, Lerman C, Pharmacogenetics of Nicotine A, Treatment C. Nicotinic acetylcholine receptor beta2 subunit gene implicated in a systems-based candidate gene study of smoking cessation. Human molecular genetics. 2008; 17:2834-2848.

28. Uhl GR, Liu QR, Drgon T, Johnson C, Walther D, Rose JE, David SP, Niaura R, Lerman C. Molecular genetics of successful smoking cessation: convergent genome-wide association study results. Arch Gen Psychiatry. 2008; 65:683-693.

29. Uhl GR, Walther D, Musci R, Fisher C, Anthony JC, Storr CL, Behm FM, Eaton WW, Ialongo N, Rose JE. Smoking quit success genotype score predicts quit success and distinct patterns of developmental involvement with common addictive substances. Molecular psychiatry. 2014; 19:50-54.

30. Thorgeirsson TE, Gudbjartsson DF, Surakka I, Vink JM, Amin N, Geller F, Sulem P, Rafnar T, Esko T, Walter S, Gieger C, Rawal R, Mangino M, et al. Sequence variants at CHRNB3-CHRNA6 and CYP2A6 affect smoking behavior. Nature genetics. 2010; 42:448-453.

31. Rowther FB, Wei W, Dawson TP, Ashton K, Singh A, Madiesse-Timchou MP, Thomas DG, Darling JL, Warr T. Cyclic nucleotide phosphodiesterase-1C (PDE1C) drives cell proliferation, migration and invasion in glioblastoma multiforme cells in vitro. Mol Carcinog. 2016; 55:268-279. 
32. Shimizu K, Murata T, Watanabe Y, Sato C, Morita H, Tagawa T. Characterization of phosphodiesterase 1 in human malignant melanoma cell lines. Anticancer Res. 2009; 29:1119-1122.

33. Levin ED, McClernon FJ, Rezvani AH. Nicotinic effects on cognitive function: behavioral characterization, pharmacological specification, and anatomic localization. Psychopharmacology (Berl). 2006; 184:523-539.

34. Gratacos M, Gonzalez JR, Mercader JM, de Cid R, Urretavizcaya M, Estivill X. Brain-derived neurotrophic factor Val66Met and psychiatric disorders: meta-analysis of case-control studies confirm association to substancerelated disorders, eating disorders, and schizophrenia. Biol Psychiatry. 2007; 61:911-922.

35. Post RM. Role of BDNF in bipolar and unipolar disorder: clinical and theoretical implications. J Psychiatr Res. 2007; 41:979-990.

36. Thorleifsson G, Walters GB, Gudbjartsson DF, Steinthorsdottir V, Sulem P, Helgadottir A, Styrkarsdottir U, Gretarsdottir S, Thorlacius S, Jonsdottir I, Jonsdottir T,
Olafsdottir EJ, Olafsdottir GH, et al. Genome-wide association yields new sequence variants at seven loci that associate with measures of obesity. Nature genetics. 2009; 41:18-24.

37. Song F, Amos CI, Lee JE, Lian CG, Fang S, Liu H, MacGregor S, Iles MM, Law MH, Lindeman NI, Montgomery GW, Duffy DL, Cust AE, et al. Identification of a melanoma susceptibility locus and somatic mutation in TET2. Carcinogenesis. 2014; 35:2097-2101.

38. Biernacka JM, Tang R, Li J, McDonnell SK, Rabe KG, Sinnwell JP, Rider DN, de Andrade M, Goode EL, Fridley BL. Assessment of genotype imputation methods. BMC proceedings. 2009; 3 Suppl 7:S5.

39. Meng S, Song F, Chen H, Gao X, Amos CI, Lee JE, Wei Q, Qureshi AA, Han J. No association between Parkinson disease alleles and the risk of melanoma. Cancer epidemiology, biomarkers \& prevention. 2012; 21:243-245.

40. Benjamini Y, Hochberg Y. Controlling the False Discovery Rate - a Practical and Powerful Approach to Multiple Testing. J Roy Stat Soc B Met. 1995; 57:289-300. 